\title{
Effect of Aerobic Exercises on Introvertover Weight Children Who Usemodern Technology
}

\author{
Dr. Asmaa Osama ${ }^{1}$, Ass. Prof.dr.NahedShukri ${ }^{1}$, MohamedAbd El Salam ${ }^{2}$, Dr. \\ Tarek $\mathrm{Omar}^{3}$ \\ ${ }^{I}$ Department of Physical Therapy for Pediatrics, Faculty of Physical Therapy Cairo University, Egypt. \\ ${ }^{2}$ Physical Therapy Specialist at Abou-KeerHospital, Faculty of physical therapy 6 October University, Egypt \\ ${ }^{3}$ General and Plastic Surgery, Faculty of Medicine, Alexandria University, Egypt
}

\begin{abstract}
Background: The increasing amount of time that people spend using computers and watching TV is a major factor in rising rates of obesity. Children who are heavily engaged in social networking have an increased chance of developing antisocial personality disorder. The Body Mass Index forage percentile growth charts are indicator to measure the size and growth patterns of children and teens. Introversion scale has good reliability .Aerobic Exercise can have positive effects on self-esteem, self-confidence and behavior in children and youth. Therefore this work studied the effect of aerobic exercise on introverted overweight children.

Methodology: One hundred introverted overweight children chosenfrom preparatory school by introversion scale and BMI for children.Quasi-experimental design was used in this study. Their ages ranged from 13to15 years. Introversion characteristic and weight again was measured before and after 3 months of treatment (3sessions /week of aerobic exercises, treadmill and bicycle for 1 hour).

Results: there is improvement in bothintroversion and over weight in $83 \%$ Improvement in only introversion (5\%), improvement only in overweight (8\%), and there is no improvement in 4\%of sample .

Conclusion: Aerobic exercises are effective modality in treatment of introverted overweight children.

Key words: Introversion / Aerobic Exercises / Overweight / Modern Technology.
\end{abstract}

\section{Introduction}

Introversion is one of the major personality traits identified in many theories of personality. People who are introverted tend to be inward turning, or focused more on internal thoughts, feelings and moods rather than seeking out external stimulation. Introversion is generally viewed as existing as part of a continuum along with extroversion. Introversion indicates one end of the scale, while extroversion represents the other end ${ }^{[1]}$.The actual ratio based on the first official random sample by the Myers-Briggs organization in 1998 showed Introverts 50.7\% and Extroverts 49.3\% [ Total Introverted: 50.7\% :Introverted Males: 54.1\%,Introverted Females: $47.5 \%]^{[2]}$ The introversion scale used in this study was developed by McCroskey to be distinct from measures of communication apprehension.. The correlations of this measure with the Personal Report of Communication Apprehension PRCA-24 have been around 0.3. Alpha reliability estimatedhas been above 0.8. Items to measure neuroticism are used as filler items and are not scored with the introversion items ${ }^{[3]}$.Body Mass Index (BMI) is a person's weight in kilograms divided by the square of height in meters. For children and teens, BMI is age and sex specific and is often referred to as BMI-for-age. In children, a high amount of body fat can lead to weight-related diseases and other health issues and being underweight can also put one at risk for health issues. High BMI can be an indicator of high body fatness ${ }^{[4]}$. BMI can be considered an alternative to direct measures of body fat. In general, BMI is an inexpensive and easy-to-perform method of screening for weight categories that may lead to health problems ${ }^{[5]}$. Spending excessive time engaging in sedentary behaviors, such as watching TV, playing video games, and other screen time activities is a major factor in rising rates of obesity worldwide ${ }^{[6]}$ Introversion is "the state of or tendency toward being wholly or predominantly concerned with and interested in one's own mental life" ${ }^{[7]}$.Obesity has been defined as "an increase in body weight resulting from an excessive increase in body fat" ${ }^{18]}$. The problem with obesity is not weight or mass but excess adipose tissue. Adipose tissue is a "major energy store in the body and its size can only increase if food (energy) intake is greater than the body's energy demands ${ }^{[9]}$. Childhood obesity is a multisystem disease with potentially devastating consequences several complications warrant special attention. As with adults, obesity in childhood causes hypertension, dyslipidemia, chronic inflammation, increased blood clotting tendency, endothelial dysfunction, and hyperinsulinaemia" increase of cardiovascular disease risk factors" known as the insulin resistance syndrome, has been identified in children as young as 5 years of age., the presence of cardiovascular disease risk factors correlated with asymptomatic coronary atherosclerosis, and lesions were more advanced in obese individuals ${ }^{[10]}$.The literature supports that exercise for the goal of weight loss should be of low to moderate intensity for a long duration (at least $45 \mathrm{~min}$ ). At low to moderate intensities, fat is the preferred fuel 
for muscles, especially if the exercise duration is greater than $45 \mathrm{~min}$. this is because there are greater stores of body fat than carbohydrate while at high intensities, the accumulation of lactic acid in the muscle inhibit fat utilization ${ }^{[11]}$.The use of diets and exercise in the treatment of overweight\& obesity is being challenged today by the public and a growing number of health care professionals, as well as obesity researchers. The challengers argue that diets are at best ineffective, and many times harmful. Most of weight loss literature is based on a subpopulation of obese people who seek clinical help from hospital- or university-based programs, and that these people do not represent the entire obese population ${ }^{[12]}$.

\section{Subjectselection and study design:}

\section{Methods}

This study was conducted on a total number of 100childern with introversion and overweight .their age range from 13 to 15 years old. A convenience sample of 100 children with consenting parents from preparatory school at Alexandria Government schools was recruited for this study. We used a quasi-experimental A-B-A design. They will be introverted according to introversion scale and over weighted according to body mass index chart. The practical work was conducted from February 2016 till June 2016.

Procedures: Evaluation procedures include Weight and Height instrument used to Measure Weight and measuring Height. Introversionscale: Eighteen statements that children make about themselves. Which indicate whether or not each statement applies to the child believe by marking whether he/she status are [Strongly Disagree = 1; Disagree 2; Undecided =3; Agree = 4; Strongly Agree = 5] Scoring system of this scale: To determine score on the Introversion Scale, we should complete the following steps: Step 1. Add scores for items $1 \& 4$,Step 2. Add the scores for items 2, 5, 7, 8, 10, 11, 13, 14, 16, \& 18, Step 3. Complete the following formula:

\section{Introversion $=12-[$ Total from Step $1+$ Total from Step 2]}

The score should be between 12 and 60. If you compute a score outside that range, you have made a mistake in computing the score. Note: Items 3, 6, 9, 12, 15, and 17 are not used in computing your introversion scale. Individuals scoring above 48 are highly introverted; those scoring below 24 have low introversion (are extraverted). Those scoring between 24 and 48 are in the moderate range. The BMI-for-age percentile growth chart: weight $(\mathrm{kg})$ divided by height in meter squared $(\mathrm{m} 2)$. After BMI is calculated for children and teens, the BMI number is plotted on Centers for Disease Control and Prevention(CDC) BMI-for-age growth charts (for either girls or boys) to obtain a percentile ranking. Percentiles are the most commonly used indicator to assess the size and growth patterns of individual children in the United States. The percentile indicates the relative position of the child's BMI number among children of the same sex and age. The growth charts show the weight status categories used with children and teens (underweight, healthy weight, overweight, and obese).BMI-forage weight status categories and the corresponding percentiles are shown in the following: [Underweight: Less than the 5 th percentile. Healthy weight: 5 th percentile to less than the 85 th percentile.Overweight:85th to less than the 95th percentile. Obese: Equal to or greater than the 95th percentile]

Treatment procedures: Children will receive especially designed therapeutic exercise program. The treatment session will last for one hour for each child and will be conducted 3 times /week for 3 successive months. The therapeutic exercise program will include the following: Treadmill exercise: Motorized treadmill 770 (E.220V, 50HZ, and 2.2 Kilowatts). This model allows the child to exercise in a safe environment with adequate space, and with controlling of all important parameters. The training sessions will be scheduled 3 days/ week for 3 successive months, with 1 or 2 rest days after each training day. The intervention lasted for 15 minutes / day. All children will participate in their regularly scheduled grouped physical therapy sessions during the duration of the study. All children will be allowed to engage in their normal everyday activities, including walking. The starting treadmill speed will be determined during the initial training session and will be increased as quickly as possible throughout the sessions. The whole 15 minutes will be at zero inclination.Bicycle:Bicyclekittler GIRO-M ( montageanleitung - Art.-Nr. 07627-000). The training sessions will be scheduled 3 days/ week for 3 successive months, with 1 or 2 rest days after each training day. The intervention lasted for 15 minutes / day. All children will participate in their regularly scheduled grouped physical therapy sessions during the duration of the study. GroupTherapy: The training sessions will be scheduled 3 days/ week for 3 successive months of aerobic exercises, with 1 or 2 rest days after each training day. The intervention lasted for 30 minutes / day. Which include:1-Side Bending Exercise.2-Knee Bending Exercise.3-Sqatting Exercise.4-Forward Bending Exercise.5Push-Up Exercise.6-Straight Leg Raising Exercise.7-Bridging Exercise ${ }^{[13][14]}$

\section{Results}

In this study, apply introversion scale on 397 children of preparatory school, 180 is extraverted or normal children $(45.3 \%)$ and 217 children of them introverted (54.7\%).217 children divided to 114 obese or normal or underweight children (28.7\%)And 103 overweight children (25.9\%). Choose 100 introvert overweight children (25.2\%) and exclude 3 children (0.8\%)Table (1). 
Table (1):Distribution of the examined students $(\mathrm{n}=397)$

\begin{tabular}{lll}
\hline Students & No. & \% \\
\hline Extravert / Normal & $\mathbf{1 8 0}$ & $\mathbf{4 5 . 3}$ \\
\hline Introvert & $\mathbf{2 1 7}$ & $\mathbf{5 4 . 7}$ \\
$\quad$ Obese or normal or underweight & 114 & 28.7 \\
$\quad$ Overweight/introvert & 103 & 25.9 \\
$\quad$ Studied cases & 100 & 25.2 \\
\hline Excluded cases & 3 & 0.8 \\
\hline
\end{tabular}

\section{Distribution of the studied students:}

The one hundred children apply 3 months treatment by treadmill, stationary bicycle and exercises 3times weekly, every time take one hour. Then, apply introversion scale and BMI on the 100 childrenbefore/after the 3 months of treatment to show the prognosis in cases. There are 83 children improved in both introversion and weight $(83 \%)$, there are 8 children improved only in weight but introversion not improved $(8 \%)$, there are 5 children improved in introversion only but not improved in weight (5\%) and there are 4 children not improved in both introversion or weight (4\%)Table (2).There's significant difference between (Pre and Post treatment)in Introversion scale, p-value is $(<0.001)$. The mean value \pm SD of pretreatment was $(41.03$ $\pm 10.36)$ and that for post treatment was $(52.86 \pm 5.0),(\mathrm{t})$ value equal $(9.394)$, The mean difference between both groups. The median of introversion scale for pretreatment was 40.50 and that for post treatment was rise up to 53.0. Percentage of change was $\uparrow 38.42 \pm 40.71$ table (3). There's significant difference between (Pre and Post treatment $)$ in BMI, p-value is $(<0.001)$. The mean value \pm SD of pretreatment was $(88.85 \pm 5.06)$ and that for post treatment was $(91.96 \pm 2.52),(\mathrm{t})$ value equal $(6.416)$, The mean difference between both groups. The median of BMI for pretreatment was 90.0 and that for post treatment was rise up to 93.0.Percentage of change was $\uparrow 3.79 \pm 5.78$ table (4).

Table (2):Distribution of the studied students $(\mathrm{n}=100)$

\begin{tabular}{|lll}
\hline & No. & \% \\
\hline Introvert and overweight students & $\mathbf{1 0 0}$ & $\mathbf{1 0 0 . 0}$ \\
\hline No improve & 4 & 4.0 \\
Weight only improve & 8 & 8.0 \\
Introversion only improve & 5 & 5.0 \\
Both improve & 83 & 83.0 \\
\hline
\end{tabular}

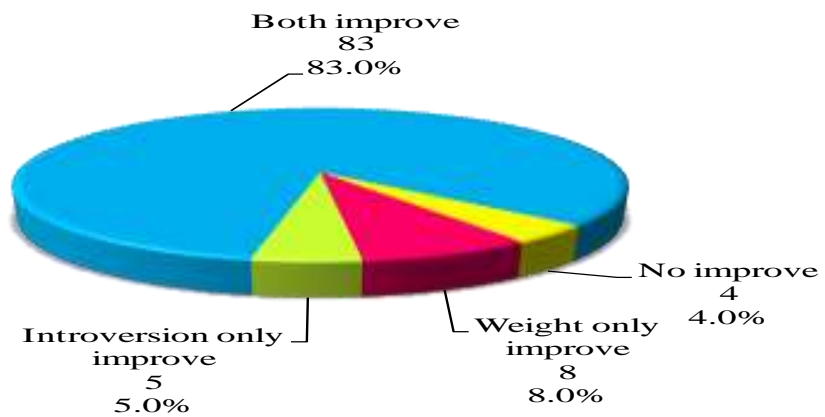

Figure (1): Distribution of the introvert and overweight student

Table (3): Comparison between the two studied periods according to scale $(\mathrm{n}=100)$

\begin{tabular}{|c|c|c|c|c|}
\hline & Before & After & $\mathbf{T}$ & $\mathbf{P}$ \\
\hline \multicolumn{5}{|l|}{ Introversion Scale } \\
\hline Min. - Max. & $25.0-60.0$ & $28.0-60.0$ & \multirow[t]{4}{*}{$9.394^{*}$} & \multirow[t]{4}{*}{$<0.001^{*}$} \\
\hline Mean \pm SD. & $41.03 \pm 10.36$ & $52.86 \pm 5.0$ & & \\
\hline Median & 40.50 & 53.0 & & \\
\hline$\%$ of change & $\uparrow 38.42 \pm 40.71$ & & & \\
\hline
\end{tabular}

$\mathrm{t}, \mathrm{p}: \mathrm{t}$ and $\mathrm{p}$ values for Paired $\mathrm{t}$-test for comparing between before and after $*$ : Statistically significant at $\mathrm{p} \leq$ 0.05

Table (4): Comparison between the two studied periods according to BMI $(\mathrm{n}=100)$

\begin{tabular}{cllll}
\hline & Before & After & T & P \\
\hline BMI $\left(\mathbf{k g} / \mathbf{m}^{\mathbf{2}}\right)$ & & & & $6.416^{*}$ \\
Min. - Max. & $73.0-99.0$ & $85.0-94.0$ & $<0.001^{*}$ \\
Mean \pm SD. & $88.85 \pm 5.06$ & $91.96 \pm 2.52$ & \\
Median & 90.0 & 93.0 & & \\
\% of change & $\uparrow \mathbf{3 . 7 9} \pm \mathbf{5 . 7 8}$ & & \\
\hline
\end{tabular}

$\mathrm{t}, \mathrm{p}: \mathrm{t}$ and $\mathrm{p}$ values for Paired t-test for comparing between before and after

*: Statistically significant at $\mathrm{p} \leq 0.05$ 


\section{Discussion}

The present study was conducted on 100 overweight introvert children. They were selected according to the criteria frompreparatory school (13 _ 15 years old) which may be supported bywakefield ${ }^{[15]}$ who reported that Children aged 10 to 16 spend an average of six and a half hours a day in front of a screen compared with around three hours in 1995, time is made up of time spent watching TV, playing games consoles, using a mobile, computer or tablet.They received a designed exercise program of 30 minutesof exercises in group therapy which supported byTartakovsky ${ }^{[16]}$ who reported that Group therapy helps you realize you're not alone, group therapy reduces isolation and alienation. It increases the sense that they are all in this together and normalizes suffering. Children also received program of 15 minutes in the form of treadmill, 15 minutes in form of stationarybicycle. Treatment was performed three times/per week for three successive months (around 36 sessions) ${ }^{[17][18]}$ and this come in agreement with Smith et.alwho reported that Different treatment strategies introduced to optimize cognition. Some of these strategies are aerobic exercises, Six months of high-intensity aerobic exercise. Children who participated in this study were assessed by introversion scale and BMI-For-age percentile growth chart test before and after three months of treatment which gives indication about the behavioral disorders changes and functional status supported by the work ofJovanovic et.al ${ }^{[19]}$ who reported that, Body mass index (BMI) is the most widespread and the simplest method for the evaluation of body mass; it is often used as a sole technique in the diagnosis of obesity in children .Over use of modern technology from children also lead to increase weight.Children sit a lot of time on their computers and tablets which reduce physical activities and sports practicing.This comes in agreement withSibly and Etnier ${ }^{[20]}$ who reported that because overweight is a marker of a long history of inactivity, overweight, sedentary children may be more likely to benefit from an exercise intervention than their active, normal weight peers .Over use of modern technology from children lead to increase children isolation and introversion. Children spend at least 6 hours on their tablets and computers for games or for their home works. They became not interact or speak with their families and friends.This comes in agreement withGwinn ${ }^{[21]}$ who reported that, children spending up to 7 hours a day attached to their iPods, smartphones, computers, and gaming consoles. And the effects to their brains are proving to be very damaging. Overuse of digital technology is resulting in the breakdown of cognitive abilities as deficits in ability to concentrate, short attention, memory span, and emotional disturbances, such as depression and isolation.

\section{References}

[1]. Rauch, J. (2003): Atlantic journal, Caring for Your Introvert. March 2003 ISSUE

[2]. Black C (2011): http://www.http://introvertzone.com/ Ratio of introverts, Introverts are taking over the world, February 14, 2011.

[3]. Eysenck, H. J. (1971): Readings in extraversion-introversion: Volume II. New York: Wiley-Interscience.

[4]. Wohlfahrt-Veje, C. et al., 2014. Body fat throughout childhood in 2647 healthy Danish children: agreement of BMI, waist circumference, skinfolds with dual X-ray absorptiometry. Eur. J. Clin. Nutr., 68(6), pp.664-70

[5]. Kuczmarski, R.J. et al., 2002. 2000 CDC Growth Charts for the United States: methods and development. Vital Health Stat. 11., 11(246), pp.1-190.

[6]. Troiano RP, Berrigan D, et al. Physical activity in the United States measured by accelerometer. Medicine \& Science In Sports \& Exercise 2008; 40(1):181-188.

[7]. A b c Merriam Webster Dictionary (2015): http://www.spanishcentral.com/translate/ABC's

[8]. Joseph,K., Ang,K., Ngo,K., Yim,G. (1997) Obesity in Children, Internet Journal of Health Promotion, URL; http://www.monash.edu.au/health/IJHP/1996/2.

[9]. Caterson,I.(1997) Obesity Part of the Metabolic Syndrome, The Clinical Biochemist Reviews, 18;1. pp11-21.

[10]. Ebbeling, C. et al (2002) Childhood obesity: public health crisis, common sense cure. The Lancet; 360: 9331, 473-482.

[11]. Abdel-Rahman, T.T.: Effects of aerobic exercises and electrolipolysison sex hormones in infertile obese women, Master Thesis, faculty of physical therapy, Cairo University, 2001.

[12]. Sothern, M.: Committed to kids weight management program research protocol. Presented at the committed to kids weight management training program. New orelans. LA, 1996.

[13]. Mattern-Baxter,K, Bellamy S, and Jim K.,(2009): Effects of Intensive Locomotor Treadmill Training on Young Children with Cerebral Palsy, 21:308-319.

[14]. Baker ,D,L, PhD, Frank L,L, PhD, MPH, Foster-Schubert K, MD, Green ,S,P, PhD, Wilkinson,W,C. PhD, McTiernan,A, MD, $\mathrm{PhD}$, Plymate RS, Fishel AM, Stennis WatsonG, Cholerton AB, Duncan EG, Mehta DP, and Craft S(2010): Effects of Aerobic Exercise on Mild Cognitive Impairment,Arch Neurol. 2010 Jan; 67(1): 71-79.

[15]. WakefieldJ(2015) :http://www.bbc.com/news/technology-32067158. Children spend six hours or more a day on screens.

[16]. Tartakovsky M(2016)https://psychcentral.com/lib/5-benefits-of-group-therapy/.

[17]. Smith JP, Potter GG, McLaren EM, and Blumenthal AJ(2013): Impact of aerobic exercise on neurobehavioral outcomes. Oct; 6(3): 139-153.

[18]. Marković-Jovanović SR, Stolić RV, Jovanović AN(2015): The reliability of body mass index in the diagnosis of obesity and metabolic risk in children ;28(5-6):515-23).

[19]. Sibley BA, Etnier JL. The relationship between physical activity and cognition in children: A meta-analysis. Pediatric Exercise Science. 2003; 15:243-256

[20]. GwinnJ (2013): http://www.alzheimers.net/Overuse of Technology Can Lead to 'Digital Dementia' 